\title{
Acidic stress induces apoptosis and inhibits angiogenesis in human bone marrow-derived endothelial progenitor cells
}

\author{
SHUAI HUANG ${ }^{1 *}$, PEIHENG HE ${ }^{1 *}$, DONGLIANG XU ${ }^{1}$, JINGLEI $^{2}{ }^{2}$, XINSHENG PENG ${ }^{1}$ and YUBO TANG ${ }^{3}$ \\ ${ }^{1}$ Department of Orthopedic Surgery, The First Affiliated Hospital of Sun Yat-Sen University; ${ }^{2}$ Department of Radiology, \\ Guangdong Academy of Medical Sciences, Guangdong General Hospital; ${ }^{3}$ Department of Pharmacy, The \\ First Affiliated Hospital of Sun Yat-Sen University, Guangzhou, Guangdong 510080, P.R. China
}

Received July 31, 2015; Accepted November 30, 2016

DOI: $10.3892 / \mathrm{ol} .2017 .6947$

\begin{abstract}
Bone marrow-derived endothelial progenitor cells (BM-EPCs) are exposed to acidotic environments in a variety of physiological and pathological conditions, including in tumors. However, the effect of acidosis on the function of BM-EPCs is still not fully understood. In the present study, BM-EPCs were isolated and cultured at an extracellular $\mathrm{pH}(\mathrm{pHe})$ of 6.5 or pHe 7.4 in vitro prior to various experiments being performed. Cellular proliferation, migration and tube formation ability were detected by DNA content quantification, Transwell assay and Matrigel-based angiogenesis assay. ELISA and western blot analysis measured protein secretion and expression, respectively. The results demonstrated that BM-EPCs cultured at pHe 6.5 compared with at pHe 7.4 demonstrated: Induced apoptosis; inhibited cellular proliferation, migration and adhesion; markedly reduced vascular endothelial growth factor (VEGF) expression; and the capacity to incorporate into vascular networks. Acidic pHe 6.5 induced ratio expression of B-cell lymphoma $2(\mathrm{Bcl} 2) / \mathrm{Bcl} 2$ associated $\mathrm{X}$-protein (Bax), which in turn induced apoptosis, and inhibited cellular proliferation and other functional activities, with involvement of activation of VEGF receptor 2, protein kinase B and p38 mitogen activated protein kinase. These observations raise the possibility that the acidic extracellular environment may perform an important role in the vasculogenesis of BM-EPCs
\end{abstract}

Correspondence to: Dr Yubo Tang, Department of Pharmacy, The First Affiliated Hospital of Sun Yat-Sen University, 58 Zhongshan Second Road, Guangzhou, Guangdong 510080, P.R. China E-mail: tangyubo@hotmail.com

Dr Xinsheng Peng, Department of Orthopedic Surgery, The First Affiliated Hospital of Sun Yat-Sen University, 58 Zhongshan Second Road, Guangzhou, Guangdong 510080, P.R. China

E-mail: pengxs66@tom.com

*Contributed equally

Key words: acidic stress, endothelial progenitor cells, angiogenesis, apoptosis, protein kinase B/vascular endothelial growth factor receptor 2, p38 mitogen activated protein kinase in tumor microenvironments. Therefore, culturing cancer cells at a lower $\mathrm{pH}$ that simulates endogenous tumor conditions may improve retention of the cellular heterogeneity identified in tumors.

\section{Introduction}

Rapid expansion of tumor mass results in inadequate vessels, a depletion of nutrients and a local increase in necrosis. This rapid increase in tumor growth is linked to cell death resulting from a microenvironment that has regions of hypoxia and a decreased extracellular $\mathrm{pH}(\mathrm{pHe})$. Extracellular acidosis (low $\mathrm{pH}$ ) is a tumor microenvironmental stressor that plays a critical role in malignant transformation, progression and metastatic dissemination (1). This microenvironment is a complex ecology of cells and dynamic milieu that provides pivotal clues on the mechanisms of tumor development and progression. Tumor angiogenesis is achieved mainly through sprouting from locally pre-existing vasculature and/or recruitment of bone marrow-derived endothelial progenitor cells (BM-EPCs). Emerging evidence implicates that the recruitment of BM-EPCs is critical for tumor vasculogenesis since tumors may acquire their vasculature by co-option of glomeruloid angiogenesis, vasculogenic mimicry, or postnatal vasculogenesis (2-4). Neovascularization in turn participates in supplying nutritional support and oxygen to growing tumors (5). This relationship has been demonstrated in a number of tumor types, including invasive breast (6), non-small cell lung (7) and prostate carcinoma (8).

Although tumor microenvironments achieve neovascularization as the tumor grows, EPCs localize near the periphery, reflecting the greater opportunity for adhesion in this region owing to increased angiogenic activity and higher vascular density (9). It has been demonstrated that EPCs adhered preferentially near the tumor periphery, coincident with the subsequent highest vascular density in a tumor model using mouse embryonic EPCs (10). Including in livers with hepatocellular carcinoma, there were more EPCs in the adjacent tissue (11). Notably, EPCs home in prior to the arrival of tumor cells, promoting metastatic growth by forming niches where cancer cells may locate and proliferate (12). It is proposed that tumor $\mathrm{pHe}$ may be variable within a tumor with localized regions of acidity, and a $\mathrm{pH}$ gradient from the periphery to 
the center of tumors was identified to be coincided with the development of small, disseminated necrosis in the tumor center $(13,14)$. The difference provides an avenue for the $\mathrm{pHe}$ and vasculogenesis of BM-EPCs in tumors.

Since a series of experiments to identify the effects of an acidic microenvironment utilizes $\mathrm{pH}$ 6.4-6.6 in vitro (15-17), the present study aimed to detect the vasculogenesis of BM-EPCs in vitro following cell exposure to $\mathrm{pHe} 6.5$ compared with a control of pHe 7.4. The present results demonstrated that, compared with pHe 7.4, pHe 6.5 may significantly induce BM-EPCs apoptosis by targeting the expression of B-cell lymphoma $2(\mathrm{Bcl} 2) / \mathrm{Bcl} 2$ associated $\mathrm{X}$-protein $(\mathrm{Bax})$ and inhibiting BM-EPCs proliferation, chemotactic migration, matrix adhesion and tube formation through the modulation of vascular endothelial growth factor (VEGF) receptor 2 (VEGFR2)-regulated protein kinase B (Akt) and p38 mitogen activated protein kinase (MAPK) signaling pathways.

\section{Materials and methods}

Isolation and cultivation of EPCs. The method of human EPCs isolation, cultivation and identification was performed as described in a previous publication (18). Human bone marrow was collected from the drill holes of the pedicle during internal spine fixation of patients with disc degenerative diseases were collected from The First Affiliated Hospital of Sun Yat-Sen University (Guangzhou, China) between October 2013 and September 2014 (10 patients; 5 males and 5 females; age range, 54-72 years; mean age, 61.27 years) at the time of surgery. Written informed consent for human bone marrow collection was obtained from the patients, and all procedures were performed in light of the guidance and approval of the Research Ethics Committee of The First Affiliated Hospital of Sun Yat-Sen University (no. 2008-55).

Cell culture. EPCs were cultured at $37^{\circ} \mathrm{C}$ with $5 \% \mathrm{CO}_{2} / 95 \%$ air in a humidified incubator, and experiments were carried out with cells in exponential growth, cultured in an acidic (pHe 6.5) or normal ( $\mathrm{pHe}$ 7.4) medium for an indicated period. The cells were plated and cultured in normal medium for $24 \mathrm{~h}$ prior to the medium being removed and replaced with normal (pHe 7.4) or acidic medium ( $\mathrm{pHe} 6.5$ ). The $\mathrm{pH}$ of the cell culture medium was adjusted with $\mathrm{HCl}$ or $\mathrm{NaOH}$ to 6.5 or 7.4 during experiments.

Assessment of cell viability and damage. A Cell Counting Kit-8 (CCK-8; Dojindo Molecular Technologies, Inc., Kumamoto, Japan) was used to evaluate living cells by combining WST-8 [2-(2-methoxy-4-nitrophenyl)-3-(4-nitrophenyl)-5-(2,4-disulf o-phenyl)-2H-tetrazolium, monosodium salt] and 1-methoxy PMS, as described previously (18). EPCs were cultured with EGM-2 medium in 96-well culture plates at $1 \times 10^{4}$ cells/well to $90 \%$ confluency, and then grown in medium at pHe 7.4 or pHe 6.5 for $24 \mathrm{~h}$ at $37^{\circ} \mathrm{C}$. Subsequent to the 24-h incubation, CCK-8 was used in line with the manufacturer's protocol and cell viability was detected using a microplate reader at $450 \mathrm{~nm}$.

Lactate dehydrogenase ( $\mathrm{LDH})$ is a stable cytosolic enzyme present in numerous types of cell. $\mathrm{LDH}$ is released into the media from damaged cells as a biomarker for cellular cytotoxicity and cytolysis. The cellular viability may be assessed in terms of LDH released from dead cells into the supernatant upon rupture of cell membrane. For this purpose, CytoTox $96^{\circledR}$ Non-Radioactive Cytotoxicity Assay kit (Promega Corporation, Madison, WI, USA) was used according to the manufacturer's protocol. Briefly, $100 \mu \mathrm{l}$ of lysis solution was added into wells containing the untreated control cells prior to the assay to obtain maximum $\mathrm{LDH}$ release. To determine the LDH content, $50 \mu \mathrm{l}$ of supernatant with $50 \mu \mathrm{l}$ of substrate solution was mixed in 96-well plates. Subsequent to a $30 \mathrm{~min}$ incubation at room temperature (RT) protected from light, the enzymatic reaction was stopped following the addition of a stop solution. The absorbance was recorded by spectrophotometry at $490 \mathrm{~nm}$ using a microplate reader. The percentage of cytotoxicity was calculated in the light using the following equation:

Percentage of cytotoxicity $=\frac{\text { Absorbance of experimental samples }}{\text { Absorbance of maximum LDH release }} \times 100$

Calcein-AM/ethidium homodimer-1 cell-survival (live-dead) assay. Cell viability was determined using a Calcein-AM/Ethidium homodimer-1 (EthD-1) Dual-Staining Assay kit (Molecular Probes; Thermo Fisher Scientific, Inc., Waltham, MA, USA). The cells were cultured in medium at $\mathrm{pH} 7.4$ or $\mathrm{pH} 6.5$ for $24 \mathrm{~h}$ at $37^{\circ} \mathrm{C}$. Following treatment, the culture medium was removed and cells were gently rinsed with warm PBS. Subsequently, $2 \mu \mathrm{M}$ calcein-AM and $4 \mu \mathrm{M}$ EthD-1 in $100 \mu \mathrm{l}$ PBS was added to each culture well and incubated at $37^{\circ} \mathrm{C}$ for $30 \mathrm{~min}$. Fluorescence signals of the cells were observed under a fluorescence microscope.

EPC apoptosis assay by flow cytometry analysis. Human EPCs were cultured with EGM-2 in 24-well culture plates at $1 \times 10^{5}$ cells/well for $24 \mathrm{~h}$ to $\sim 90 \%$ confluency, then treated with medium of pHe 7.4 or pHe 6.5 for $24 \mathrm{~h}$ at $37^{\circ} \mathrm{C}$. Cells were gently trypsinized, washed with PBS, re-suspended in binding buffer, and then incubated with Annexin V-fluorescein isothiocyanate (FITC) and propidium iodide (PI) at RT for $10 \mathrm{~min}$ in the dark. Flow cytometry analysis was performed to estimate cell apoptosis and necrosis. The percentage of apoptotic cells (Annexin V positive and PI negative) and necrotic cells (Annexin $\mathrm{V}$ and PI positive) was investigated.

EPCs matrix adhesion assay. The cell-matrix adhesion assay was used as previously described (18). Human BM-EPCs were cultured for $24 \mathrm{~h}$ to $90 \%$ confluence, and treated with pHe 7.4 or pHe 6.5 for $24 \mathrm{~h}$ at $37^{\circ} \mathrm{C}$ as above. Subsequently, BM-EPCs at $1 \times 10^{4}$ cells/well were replated onto fibronectin (BD Biosciences, San Jose, CA, USA) -coated 96-well culture plates, and incubated for $30 \mathrm{~min}$ at $37^{\circ} \mathrm{C}$. Following incubation, PBS was used to remove non-adherent cells by washing 3 times. The adherent cells were fixed with $4 \%$ paraformaldehyde for $20 \mathrm{~min}$, washed with PBS, and stained with $100 \mu \mathrm{l}$ $0.1 \%$ crystal violet for $30 \mathrm{~min}$ at RT. Adherent cells were counted under a phase contrast microscope by independent investigators.

EPCs migration assay. The cell migration assay was performed as described previously (18). Cell migration was detected using the Transwell system (Costar; Corning Life Sciences, Acton, MA, USA) with $6.5 \mathrm{~mm}$ diameter polycarbonate filters $(8 \mu \mathrm{m}$ 
pore size). BM-EPCs were briefly seeded onto chemotaxis filters in $100 \mu \mathrm{l}$ EBM-2 medium, and $600 \mu \mathrm{l}$ of pHe 7.4 or pHe 6.5 EGM-2 medium was added to the lower chamber to evaluate the effect of acidosis on cellular migration.

Subsequent to a 12 -h migration period, non-migrating cells were completely removed from the top surface of the membrane by cotton swab, and attached cells were fixed with $95 \%$ ethanol for $10 \mathrm{~min}$ and stained with $0.1 \%$ crystal violet. The plate was immersed in fresh tap water to remove excess dye. Cells that have migrated through the filter pores from the underside of the filter were then counted in 10 random fields of view under light microscopy at x100 magnification (Carl Zeiss Microimaging, Thornwood, NY, USA).

EPCs capillary-like tube formation assay. The capillary-like tube formation assay was performed as previously described (18). Matrigel (BD Biosciences, San Jose, CA, USA) was added to each 96 -well plate at $4^{\circ} \mathrm{C}$ and allowed to polymerize in an incubator at $37^{\circ} \mathrm{C}$ for $30 \mathrm{~min}$. A fraction of $1.2 \times 10^{4}$ cells/well were seeded into the Matrigel and incubated for $18 \mathrm{~h}$ under the condition of $\mathrm{pHe} 7.4$ or pHe 6.5 to allow capillary tube formation. The images of the capillary network were recorded and the tube lengths were counted using Scion Image software 4.03 (Scion Corp., Frederick, MD, USA).

ELISA. The concentrations of VEGF, basic fibroblast growth factor (bFGF) and interleukin-8 (IL-8) in the culture medium of BM-EPCs were determined using a commercial human ELISA kit based on appropriate and validated sets of monoclonal antibodies (ExCell Biology Inc., Shanghai, China). BM-EPCs were cultured for $24 \mathrm{~h}$ to $90 \%$ confluency and treated with a medium of pHe 6.5 or pHe 7.4 for 24 h. Following treatment, the culture medium was collected and stored at $-80^{\circ} \mathrm{C}$ to be used for the ELISA assay. All experiments were performed in at least triplicate and the absorbance was measured at $450 \mathrm{~nm}$.

Western blot analysis. Proteins were extracted from BM-EPCs using radioimmunoprecipitation assay buffer (Santa Cruz Biotechnology,Inc.,Dallas, TX,USA). The protein concentration was measured using a BCA protein assay kit by spectrophotometry at $562 \mathrm{~nm}$ according to the manufacturer's protocol (Thermo Fisher Scientific, Inc., Waltham, MA, USA). In total, $30 \mu \mathrm{g}$ denatured proteins were subjected to $10 \%$ SDS-PAGE. Separated proteins were transferred to a polyvinylidene difluoride membrane. Subsequent to being blocked with $5 \%$ BSA buffer for $1 \mathrm{~h}$, the membrane was sequentially incubated with primary antibodies against p-VEGFR2 (\#2474), VEGFR2 (\#9698), p-Akt (\#4060), Akt (\#4691), p-p38 MAPK (\#4511), p38 MAPK (\#8690) (dilution for all, 1:1,000; all from Cell Signaling Technology, Inc., Danvers, MA, USA) under gentle agitation overnight at $4^{\circ} \mathrm{C}$. Following washing, the membranes were incubated with a horseradish peroxidase-conjugated secondary antibody at a dilution of 1:2,000 (\#7074; Cell Signaling Technology Inc.) for $1 \mathrm{~h}$ at RT. Immunoreactive bands were detected using enhanced chemiluminescence reagents (GE Healthcare Life Sciences, Marlborough, MA, USA). The values of band intensities were quantified by Quantity One version 4.6.2 software (Bio-Rad Laboratories, Inc., Hercules, CA, USA) to the respective protein loading controls. All immunoblots are representative of $\geq 3$ independent experiments.
Statistical analysis. Numerical data are presented as the mean \pm standard deviation from $\geq 3$ individual experiments with cells from different donors. Statistical comparisons between groups were performed by one-way analysis of variance followed by the Student's t-test using SPSS 16.0 software package (SPSS, Inc., Chicago, IL, USA). P<0.05 was considered to indicate a statistically significant difference.

\section{Results}

Acidic stress induces cell death in BM-EPCs. EPCs were cultured in serum-free conditions in an acidic (pHe 6.5) or normal (pHe 7.4) medium for $48 \mathrm{~h}$. The cells were then stained with calcein AM to visualize live cells and EthD-1 to visualize dead cells. When incubated in pHe 7.4 almost all cells were alive, however exposure to pHe 6.5 for $24 \mathrm{~h}$ induced a significant level of cell injury, as indicated by cell contraction and nuclear membrane creasing (Fig. 1A).

In addition, the present study quantified the rate of cell survival under acidic conditions. As presented in Fig. 1B, EPCs grown at pHe 6.5 suppressed EPCs proliferation, and cell number after $48 \mathrm{~h}$ was $51.4 \%$ of pHe $7.4(\mathrm{P}=0.039)$. Furthermore, the rate of cytotoxicity significantly increased to $61.1 \%$ following exposure to pHe 6.5 compared with exposure to $\mathrm{pHe} 7.4$, which was demonstrated by elevated levels of LDH (Fig. 1C; $\mathrm{P}=0.004$ ).

Acidic stress induces cell apoptosis of BM-EPCs. To observe the possible effects of acidic stress on cell apoptosis, the present study examined cell apoptosis by Annexin V-FITC and PI double staining flow cytometry. As presented in Fig. 2A and B, the apoptosis rate was significantly increased (from 3.2 to $19.7 \%$ ) subsequent to cells being exposed to pHe 6.5 for $24 \mathrm{~h}$, compared with cells exposed to pHe $7.4(\mathrm{P}<0.001)$. Furthermore, western blot analysis demonstrated that acidic stress caused a profound upregulation of pro-apoptotic Bax and a downregulation of anti-apoptotic $\mathrm{Bcl}-2$ expression in BM-EPCs (Fig. 2C and D; P<0.001).

Acidic stress inhibits migration and cell adhesion to the extracellular matrix (ECM) of BM-EPCs. It is known that cell mobility and maintenance of cell survival signaling are essential for tubule formation. To evaluate the migratory abilities of BM-EPCs under the acidic stress in vitro, the present study examined the cellular response of BM-EPCs to migration using a Transwell assay. The cells demonstrated an impaired ability to migrate (Fig. 3A and B) in the medium of pHe 6.5, compared with the control group ( $\mathrm{pHe} 7.4 ; \mathrm{P}=0.023$ ).

To investigate the possibility that acidic stress affects the binding of BM-EPCs to the extracellular matrix (ECM), cells were incubated at pHe 6.5 or pHe 7.4 for $24 \mathrm{~h}$. Subsequent to re-plating onto human fibronectin-coated culture plates, EPCs exhibited a significant decrease in the number of adhesive cells following a $30 \mathrm{~min}$ incubation (Fig. 3C and D; P=0.028).

Acidic stress inhibits capillary-like tube formation of $B M-E P C s$. The aforementioned observation that acidic stress affects the cell mobility prompted us to examine its possible effect on vasculogenesis, which was investigated using the capillary tube formation assay on Matrigel. When EPCs 
A
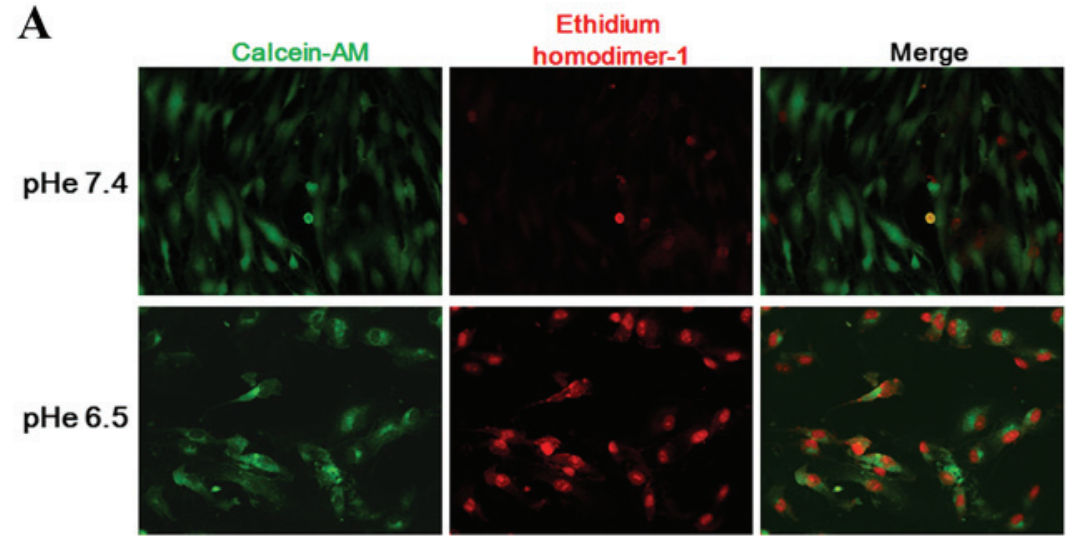

B

C
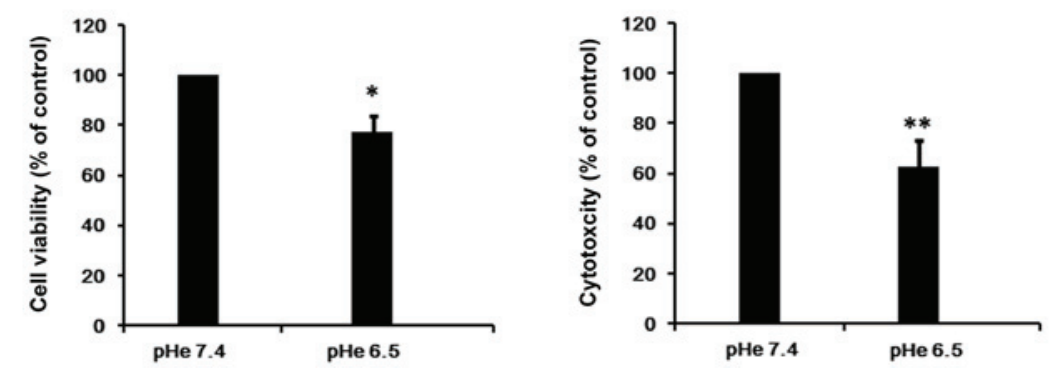

Figure 1. Acidosis inhibits cell viability in BM-EPCs. Cells were incubated at either at pHe 7.4 or pHe 6.5 for $24 \mathrm{~h}$ and washed with PBS. (A) Cell survival was monitored using a calcein-AM/ethidium homodimer-1 double staining. Representative images were captured from the stained BM-EPCs of the indicated treatment. (B) Cellular viability was evaluated by quantification of succinate dehydrogenase. (C) Cell death was evaluated by lactate dehydrogenase assay. All data are expressed as the mean \pm standard deviation, ${ }^{*} \mathrm{P}<0.05$ vs. pHe 7.4 group, ${ }^{* *} \mathrm{P}<0.01$ vs. pHe 7.4 group. BM-EPCs, bone marrow derived-endothelial progenitor cells; -AM, acetoxymethyl.

A
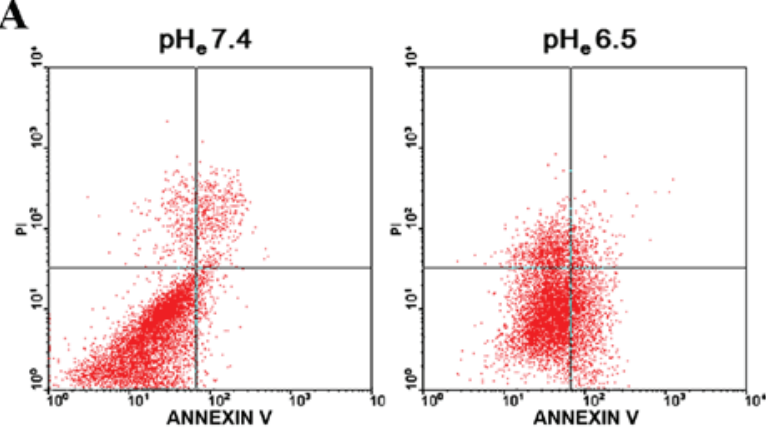

C

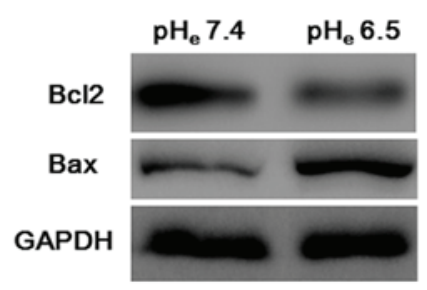

B

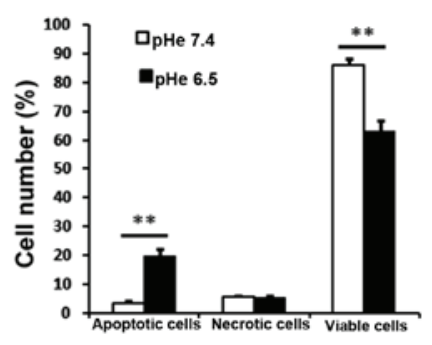

D

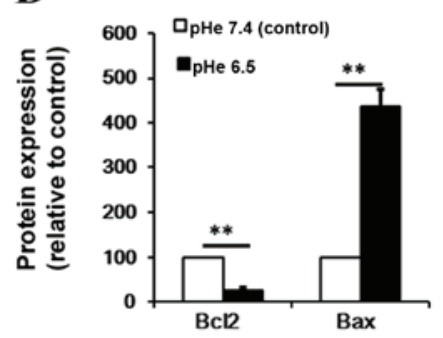

Figure 2. Acidosis induces cell apoptosis involved the modulation of Bcl-2/Bax expression. BM-EPCs were incubated either at pHe 7.4 or pHe 6.5 for $24 \mathrm{~h}$. (A) Cells were harvested and labeled with a combination of Annexin V-fluorescein isothiocyanate and propidium iodide, cell apoptosis was determined by flow cytometry. (B) The percentage of apoptotic cells, necrotic cells and viable cells were calculated based on the flow-cytometric analysis. (C) Total cell lysates were prepared and subjected to SDS-PAGE, followed by western blot analysis. The immunoblots presented are representative of at least 3 independent experiments with comparable results. (D) Densitometric analysis was performed using Quantity One software. All data are expressed as the mean \pm standard deviation. ${ }^{* *} \mathrm{P}<0.01$ vs. pHe 7.4 group. Bcl-2, B-cell lymphoma 2; Bax, Bcl-2 associated X-protein; BM-EPCs, bone marrow derived-endothelial progenitor cells.

were seeded on growth factor reduced, two-dimensional Matrigel, defined tube-like structures were formed in
pHe 7.4 (Fig. 3E and F; P=0.002). However, the majority of cells cultured in medium at pHe 6.5 remained in individual 
A

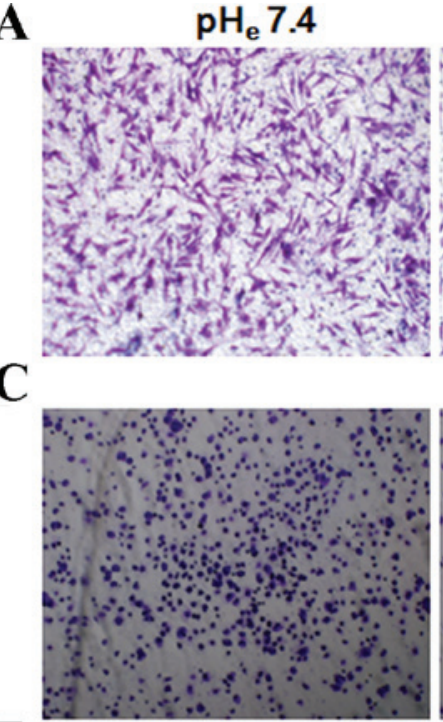

$\mathbf{E}$

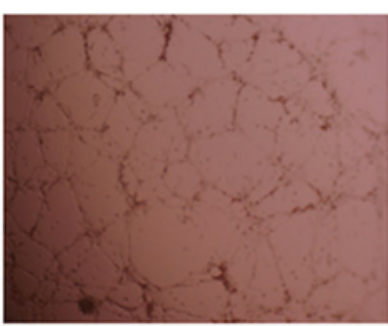

$\mathrm{pH}_{\mathrm{e}} 6.5$
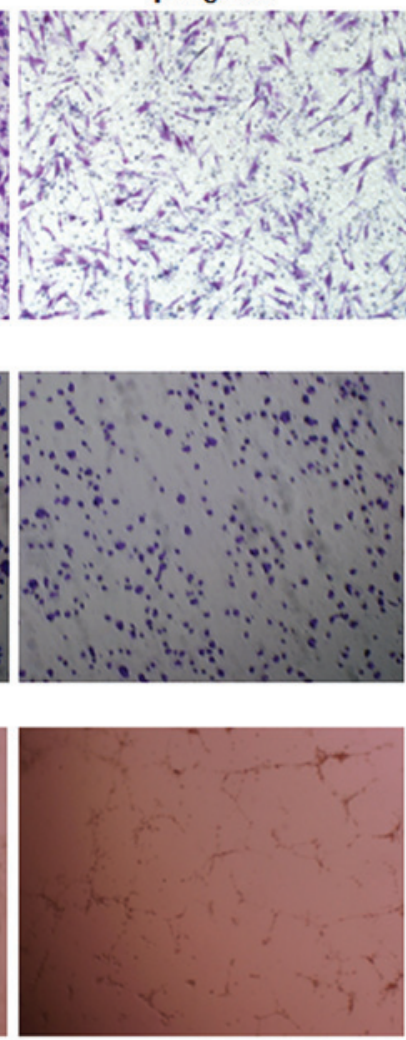

B

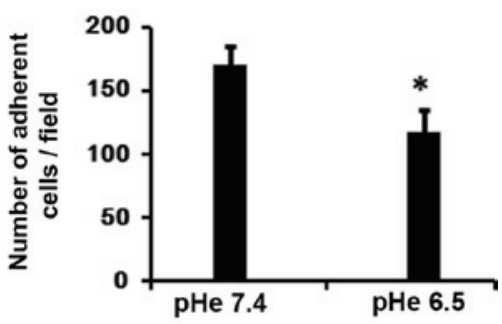

D

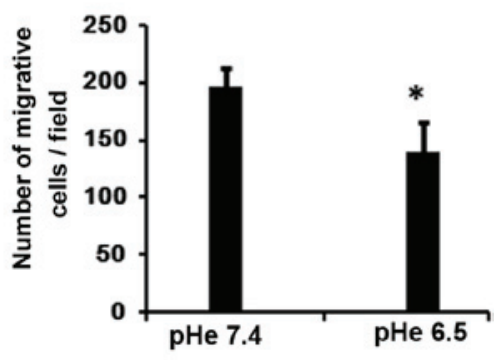

F

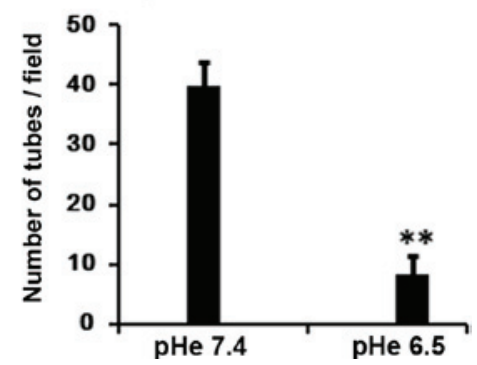

Figure 3. Acidosis inhibits cell motility, cell-matrix adhesion and capillary structure formation in BM-EPCs. (A) Transwell chemotaxis assay was performed on BM-EPCs with medium of pHe 7.4 or pHe 6.5 in the lower chamber. To quantify the migrated EPCs on the membrane, the upper side of the membrane was washed and wiped with a cotton swab. Transwell membranes were stained with crystal violet and the migrated cells were examined using inverted microscopy. (B) The number of migrated cells was quantified by manual individual cell counting of 10 random fields. (C) BM-EPCs were incubated in a medium of pHe 7.4 or pHe 6.5 for $24 \mathrm{~h}$. Cell adhesion to extracellular matrix was performed on fibronectin treated plates for 30 min followed by the staining of adherent cells with crystal violet. (D) The number of adherent cells was quantified by performing cell counts of 10 random fields. (E) Cells were seeded into the Matrigel and incubated for $18 \mathrm{~h}$ under the condition of $\mathrm{pHe} 7.4$ or $\mathrm{pHe} 6.5$. The images of capillary tube formation were recorded using inverted light microscopy. (F) Five independent fields were assessed for each well and the average numbers of tubes/x40 magnification were determined. All data are expressed as the mean \pm standard deviation. ${ }^{*} \mathrm{P}<0.05$ vs. pHe 7.4 group, ${ }^{* *} \mathrm{P}<0.01$ vs. pHe 7.4 group. BM-EPCs, bone marrow derived-endothelial progenitor cells.

clusters or ovoid colonies. These data suggest that acidic stress inhibits capillary-like tube formation of BM-EPCs in vitro.

Acidic stress inhibits the secretion of VEGF, bFGF, and IL-8 in $B M-E P C s$. Since VEGF alters the marrow microenvironment from a quiescent state to a pro-angiogenic and pro-tumorigenic environment, it plays a pivotal role in the regulation of angiogenesis as well as cell function. Therefore, the present study assessed the secretion level of VEGF in the supernatant of BM-EPCs. Subsequent to a 24-h incubation, the production of VEGF in the supernatant of BM-EPCs was significantly reduced in the acidic medium treatment ( $\mathrm{pHe} 6.5$ ) compared with the control group (pHe 7.4; Fig. 4A; $\mathrm{P}=0.005$ ). Additional experiments revealed that the secretion of bFGF in cells also declined markedly following exposure to acidic stress ( $\mathrm{pHe} 6.5$ ) compared with the normal conditions (pHe 7.4; Fig. 4B; $\mathrm{P}=0.007)$. However, the IL-8 secretion was activated under the acidic stress in BM-EPCs (Fig. 4C; $\mathrm{P}=0.009$ ).

Acidic stress inhibits the phosphorylation of VEGFR2, Akt, and p38 MAPK. Interaction of VEGF with VEGFR2 leads to the activation of various downstream signaling molecules responsible for EPCs proliferation, migration and survival.
To additionally delineate the mechanisms that contribute to the angiogenesis inhibition effect of acidic stress, the present study examined the signaling molecules involved in the VEGF pathway using western blot analysis. Under the conditions used in the present experiments, the phosphorylation of VEGFR2 was suppressed by acidic stress (Fig. $5 \mathrm{~A} ; \mathrm{P}=0.001$ ). Thus, the anti-angiogenic property of acidic extracellular conditions may be in part due to the inhibition of VEGFR2. Additionally, upon exploration of the key pathway components that drive the endothelial cell function in angiogenesis, the present study observed that acidic extracellular conditions may effectively repress VEGF-triggered activation of the signaling cascade, including phosphorylated Akt $(\mathrm{P}=0.001)$ and phosphorylated p38 MAPK $(\mathrm{P}=0.001)$ in BM-EPCs (Fig. 5). This result supports that acidic stress may suppress tumor angiogenesis by blocking these signaling pathways.

\section{Discussion}

Acidosis was identified as an important stress factor triggering apoptosis in coronary endothelial cells under ischemic conditions through activation of caspase-12 in a previous study (19). In the present study, it was identified that acidic 
A

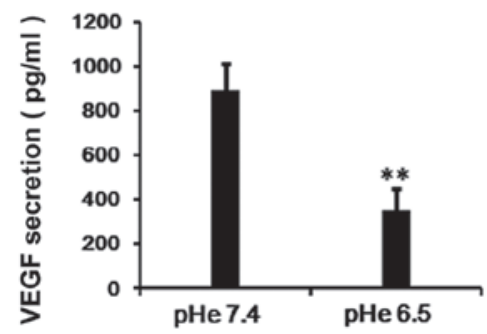

B

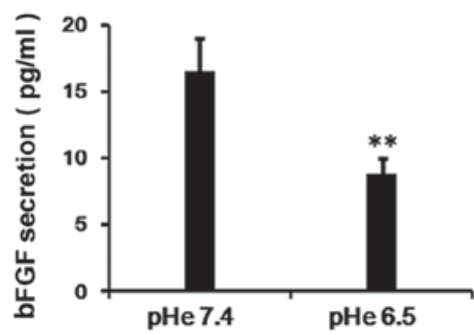

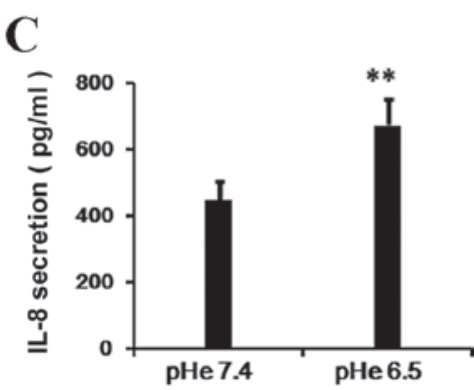

Figure 4. Acidosis inhibits VEGF secretion of BM-EPCs. Cells were cultured until confluency in 96-well plates and subsequently incubated either at pHe 7.4 or pHe 6.5. Cell culture supernatants were collected subsequent to a $24 \mathrm{~h}$ incubation and the secretion of (A) VEGF, (B) bFGF and (C) IL-8 were determined by ELISA. All data are expressed as the mean \pm standard deviation. ${ }^{* *} \mathrm{P}<0.01 \mathrm{vs.} \mathrm{pHe} 7.4$ group. VEGF, vascular endothelial growth factor; BM-EPCs, bone marrow derived-endothelial progenitor cells; bFGF, basic fibroblast growth factor; IL-8, interleukin-8.

A

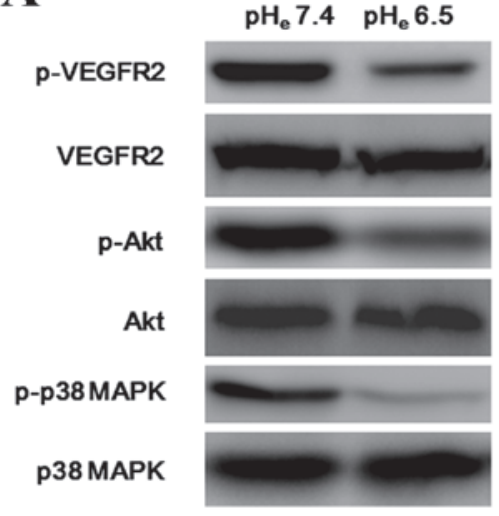

B

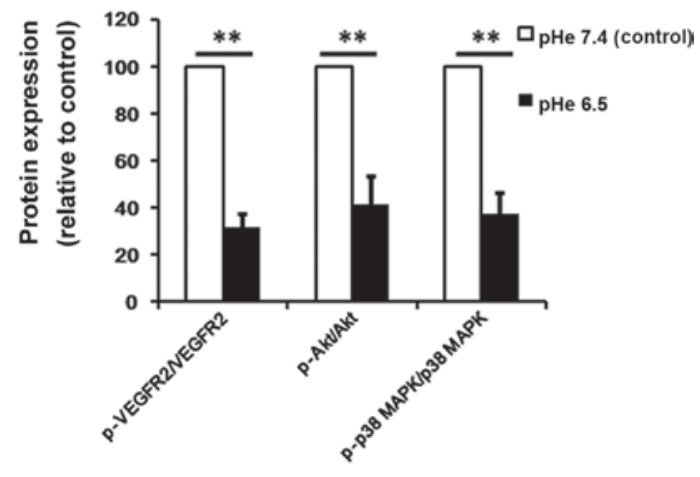

Figure 5. Acidosis inhibits the phosphorylation of VEGFR2, Akt and p38 MAPK in BM-EPCs. (A) BM-EPCs were incubated in a medium of pHe 7.4 or pHe 6.5 on Matrigel for $24 \mathrm{~h}$, total protein $(30 \mu \mathrm{g})$ was isolated from the cells, subject to western blotting and probed with specific antibodies. The immunoblots presented here are representative of at least 3 independent experiments with similar results. (B) Densitometric analysis of band intensities normalized to the total proteins or GAPDH are presented. All data are presented as the mean \pm standard deviation. ${ }^{* *} \mathrm{P}<0.01$ vs. pHe 7.4 group. VEGFR2, vascular endothelial growth factor receptor 2; Akt, protein kinase B; MAPK, mitogen activated protein kinase; BM-EPCs, bone marrow derived-endothelial progenitor cells; p-, phosphorylated.

stress may induce cell apoptosis, and inhibit cell proliferation, matrix adhesion, and migration and markedly reduce VEGF expression and the capacity to incorporate into the functional vascular networks in BM-EPCs.

Tumor neovascularization is a precisely coordinated process characterized by vessel expansion in the early phases and extensive neovessel formation in rapidly growing tumors (20). Importantly, it has been suggested that vasculogenesis by EPCs as well as angiogenesis plays a critical role in the production of blood vessels in tumor microenvironments $(18,21)$. A kinetic analysis of EPC contribution as a function of tumor growth demonstrated that EPCs are recruited to the tumor periphery preceding neovessel formation, and then EPCs differentiate into endothelial cells and incorporate into a subset of sprouting tumor neovessels luminally (4). EPCs localize near the periphery, reflecting the greater opportunity for adhesion in this region owing to increased angiogenic activity and higher vascular density (9). Interestingly, within the necrotic areas of a tumor, glycolysis and cessation of $\mathrm{CO}_{2}$ production and proton-binding structures are exposed to alleviate the acidosis of the tissue during sustained necrosis (22). The present results suggest that acidic stress may suppress the angiogenesis of EPCs that may result in the inhibition of neovasculogenesis in tumor, and pHe may be the reason of EPCs localize near the periphery and higher vascular density in periphery region of a tumor.

It is reported that hypercarbic acidosis enhances the mRNA expression of VEGF and the secretion of bFGF (23). The effect of acidosis on the inhibition of endothelial cell function may be explained by different mechanisms other than enhanced expression of VEGF and bFGF, including diminished affinity of the growth factors for their associated receptors, diminished receptor numbers, or inhibition of the intracellular signals triggered by the agonist-receptor interaction (24-26). The present study observed that the level of VEGF production dramatically decreased in BM-EPCs following inoculation in the condition of pHe 6.5 compared with pHe 7.4, which may be through the inhibition of VEGFR-2 expression.

Conflicting results have been produced in previous studies designed to investigate whether acidic stress ( $\mathrm{pHe}<7.0$ ) may promote invasive growth and metastatic dissemination of tumors (27). Human melanoma cells cultured in an acidic environment in vitro were identified to show enhanced invasiveness compared with the normal condition (28), and increasing the $\mathrm{pH}$ of metastatic breast tumors was associated with reduced formation of spontaneous metastases in vivo (29). However, enhanced invasiveness was not observed following acidosis exposure in similar experiments with rodent fibrosarcoma cell 
lines (30). However, emerging evidence suggests that solid tumors are commonly characterized by a unique pathophysiological microenvironment, and extracellular acidosis (low $\mathrm{pH}$ ) is a typical tumor microenvironmental stressor (31-33). Acute acidosis has been reported to inhibit proliferation and increase apoptosis of tumor cells $(34,35)$, as well as inhibit angiogenesis in the aortic ring vessel outgrowth model (36). The present results demonstrated that severe acidosis led to marked cell death, which may inhibit cellular activities including cell-matrix adhesion, chemotactic migration and capillary tube formation in BM-EPCs.

VEGF is one of the most potent angiogenic cytokines that has strong abilities to promote proliferation of vascular cells. It was identified that EPCs provide both instructive (release of angiogenic cytokines) and structural (vessel incorporation and stabilization) functions that facilitate the initiation of vessel formation at the site of tumor neovasculogenesis. The recruitment of EPCs to the tumor bed contributed to the initiation of a proangiogenic program. Meanwhile, it was also identified that the activation of VEGFR2, Akt and p38 MAPK was dramatically attenuated by the extracellular acidosis. Therefore, the present data demonstrates that acidosis inhibits cell functional activities, which may be due to a mechanism that blocks the VEGF/VEGFR2 axis, specifically targeting Akt and p38 MAPK signaling pathways.

In summary, the present study demonstrates that acidic stress inhibits the angiogenic functions of BM-EPCs that are required for tumor neovascularization to occur. Additional studies on the characterization of molecular mechanisms by which various pHe conditions modulate the function and gene expression of BM-EPCs will be necessary to reveal the pathophysiological relevance of these findings.

\section{Acknowledgements}

The present study was supported by the National Natural Science Foundation of China (grant nos. 81272938 and 81402227), and the National Natural Science Foundation of Guangdong (grant no. 2014A030310157).

\section{References}

1. Kallinowski F, Schlenger KH, Runkel S, Kloes M, Stohrer M, Okunieff P and Vaupel P: Blood flow, metabolism, cellular microenvironment, and growth rate of human tumor xenografts. Cancer Res 49: 3759-3764, 1989.

2. De Palma M and Naldini L: Role of haematopoietic cells and endothelial progenitors in tumour angiogenesis. Biochim Biophys Acta 1766: 159-166, 2006.

3. Spring H, Schuler T, Arnold B, Hämmerling GJ and Ganss R: Chemokines direct endothelial progenitors into tumor neovessels. Proc Natl Acad Sci USA 102: 18111-18116, 2005.

4. Nolan DJ, Ciarrocchi A, Mellick AS, Jaggi JS, Bambino K, Gupta S, Heikamp E, McDevitt MR, Scheinberg DA, Benezra R and Mittal V: Bone marrow-derived endothelial progenitor cells are a major determinant of nascent tumor neovascularization Genes Dev 21: 1546-1558, 2007.

5. Collet G, Skrzypek K, Grillon C, Matejuk A, El Hafni-Rahbi B, Lamerant-Fayel $\mathrm{N}$ and Kieda C: Hypoxia control to normalize pathologic angiogenesis: Potential role for endothelial precursor cells and miRNAs regulation. Vascul Pharmacol 56: 252-261, 2012.

6. Weidner N, Semple JP, Welch WR and Folkman J: Tumor angiogenesis and metastasis-correlation in invasive breast carcinoma. N Engl J Med 324: 1-8, 1991.
7. Macchiarini P, Fontanini G, Hardin MJ, Squartini F and Angeletti CA: Relation of neovascularisation to metastasis of non-small-cell lung cancer. Lancet 340: 145-146, 1992.

8. Weidner N, Carroll PR, Flax J, Blumenfeld W and Folkman J: Tumor angiogenesis correlates with metastasis in invasive prostate carcinoma. Am J Pathol 143: 401-409, 1993.

9. Davidoff AM, Ng CY, Brown P, Leary MA, Spurbeck WW, Zhou J, Horwitz E, Vanin EF and Nienhuis AW: Bone marrow-derived cells contribute to tumor neovasculature and, when modified to express an angiogenesis inhibitor, can restrict tumor growth in mice. Clin Cancer Res 7: 2870-2879, 2001.

10. Vajkoczy P, Blum S, Lamparter M, Mailhammer R, Erber R, Engelhardt B, Vestweber D and Hatzopoulos AK: Multistep nature of microvascular recruitment of ex vivo-expanded embryonic endothelial progenitor cells during tumor angiogenesis. J Exp Med 197: 1755-65, 2003.

11. Yu D, Sun X, Qiu Y, Zhou J, Wu Y, Zhuang L, Chen J and Ding Y: Identification and clinical significance of mobilized endothelial progenitor cells in tumor vasculogenesis of hepatocellular carcinoma. Clin Cancer Res 13: 3814-3824, 2007.

12. Dome B, Hendrix MJ, Paku S, Tóvári J and Tímár J: Alternative vascularization mechanisms in cancer: Pathology and therapeutic implications. Am J Pathol 170: 1-15, 2007.

13. Kallinowski $\mathrm{F}$ and Vaupel $\mathrm{P}: \mathrm{pH}$ distributions in spontaneous and isotransplanted rat tumours. Br J Cancer 58: 314-321, 1988.

14. Gerweck LE and Seetharaman K: Cellular $\mathrm{pH}$ gradient in tumor versus normal tissue: Potential exploitation for the treatment of cancer. Cancer Res 56: 1194-1198, 1996.

15. Hjelmeland AB, Wu Q, Heddleston JM, Choudhary GS, MacSwords J, Lathia JD, McLendon R, Lindner D, Sloan A and Rich JN: Acidic stress promotes a glioma stem cell phenotype. Cell Death Differ 18: 829-840, 2011.

16. Dietl K, Renner K, Dettmer K, Timischl B, Eberhart K, Dorn C, Hellerbrand C, Kastenberger M, Kunz-Schughart LA, Oefner PJ, et al: Lactic acid and acidification inhibit TNF secretion and glycolysis of human monocytes. J Immunol 184: 1200-1209, 2010.

17. Kumar S, Reusch HP and Ladilov Y: Acidic pre-conditioning suppresses apoptosis and increases expression of Bcl-xL in coronary endothelial cells under simulated ischaemia. J Cell Mol Med 12: 1584-1592, 2008.

18. Huang S, Peng L, Tang Y, Zhang L, Guo W, Zou X and Peng X: Hypoxia of PC-3 prostate cancer cells enhances migration and vasculogenesis in vitro of bone marrow-derived endothelial progenitor cells by secretion of cytokines. Oncol Rep 29: 2369-2377, 2013.

19. Kumar S, Kasseckert S, Kostin S, Abdallah Y, Schafer C, Kaminski A, Reusch HP, Piper HM, Steinhoff G and Ladilov Y: Ischemic acidosis causes apoptosis in coronary endothelial cells through activation of caspase-12. Cardiovasc Res 73: 172-180, 2007.

20. Ryschich E, Schmidt J, Hämmerling GJ, Klar E and Ganss R: Transformation of the microvascular system during multistage tumorigenesis. Int J Cancer 97: 719-725, 2002.

21. Ahn GO and Brown JM: Role of endothelial progenitors and other bone marrow-derived cells in the development of the tumor vasculature. Angiogenesis 12: 159-164, 2009.

22. Vaupel PW, Frinak S and Bicher HI: Heterogeneous oxygen partial pressure and $\mathrm{pH}$ distribution in $\mathrm{C} 3 \mathrm{H}$ mouse mammary adenocarcinoma. Cancer Res 41: 2008-2013, 1981.

23. D'Arcangelo D, Facchiano F, Barlucchi LM, Melillo G, Illi B, Testolin L, Gaetano C and Capogrossi MC: Acidosis inhibits endothelial cell apoptosis and function and induces basic fibroblast growth factor and vascular endothelial growth factor expression. Circ Res 86: 312-318, 2000.

24. Dairaghi DJ, Oldham ER, Bacon KB and Schall TJ: Chemokine receptor CCR3 function is highly dependent on local $\mathrm{pH}$ and ionic strength. J Biol Chem 272: 28206-28209, 1997.

25. French AR, Tadaki DK, Niyogi SK and Lauffenburger DA: Intracellular trafficking of epidermal growth factor family ligands is directly influenced by the $\mathrm{pH}$ sensitivity of the receptor/ligand interaction. J Biol Chem 270: 4334-4340, 1995.

26. Schmedtje JF Jr, Liu WL and Chen Y: pH is critical to the regulation of expression of the beta 2-adrenergic receptor gene in hypoxia. Biochim Biophys Acta 1314: 25-33, 1996.

27. Rofstad EK: Microenvironment-induced cancer metastasis. Int J Radiat Biol 76: 589-605, 2000.

28. Martínez-Zaguilán R, Seftor EA, Seftor RE, Chu YW, Gillies RJ and Hendrix MJ: Acidic $\mathrm{pH}$ enhances the invasive behavior of human melanoma cells. Clin Exp Metastasis 14: 176-186, 1996. 
29. Robey IF, Baggett BK, Kirkpatrick ND, Roe DJ, Dosescu J, Sloane BF, Hashim AI, Morse DL, Raghunand N, Gatenby RA and Gillies RJ: Bicarbonate increases tumor $\mathrm{pH}$ and inhibits spontaneous metastases. Cancer Res 69: 2260-2268, 2009.

30. Cuvier C, Jang A and Hill RP: Exposure to hypoxia, glucose starvation and acidosis: Effect on invasive capacity of murine tumor cells and correlation with cathepsin $(\mathrm{L}+\mathrm{B})$ secretion. Clin Exp Metastasis 15: 19-25, 1997.

31. Tomida A and Tsuruo T: Drug resistance mediated by cellular stress response to the microenvironment of solid tumors. Anticancer Drug Des 14: 169-177, 1999.

32. Tannock IF and Rotin D: Acid pH in tumors and its potential for therapeutic exploitation. Cancer Res 49: 4373-4384, 1989.

33. Flacke JP, Kumar S, Kostin S, Reusch HP and Ladilov Y: Acidic preconditioning protects endothelial cells against apoptosis through p38- and Akt-dependent Bcl-xL overexpression. Apoptosis 14: 90-96, 2009.
34. Putney LK and Barber DL: Na-H exchange-dependent increase in intracellular $\mathrm{pH}$ times $\mathrm{G} 2 / \mathrm{M}$ entry and transition. J Biol Chem 278: 44645-44649, 2003.

35. Smallbone K, Maini PK and Gatenby RA: Episodic, transient systemic acidosis delays evolution of the malignant phenotype: Possible mechanism for cancer prevention by increased physical activity. Biol Direct 5: 22, 2010.

36. Burbridge MF, West DC, Atassi G and Tucker GC: The effect of extracellular $\mathrm{pH}$ on angiogenesis in vitro. Angiogenesis 3: 281-288, 1999. 